\title{
THE SOLVENT ACTION OF CARBONIC ACID UPON THE CARBONATES OF HEAVY METALS.
}

\author{
By C. A. SEYLER, B.Sc., F.I.C. \\ (Read at the Meeting, November 4, 1908.)
}

E. F. Frex (Journ. Amer. Chem. Soc., 1908, 30, 1366) has shown that the basic carbonate obtained by precipitation of cupric salts with sodium carbonate, when left in contact with water containing carbonic acid, attains a constant composition and solubility similar to natural malachite, $\mathrm{CuCO}_{3} \cdot \mathrm{Cu}(\mathrm{OH})_{2}$, except in the degree of hydration. The solubility was found to increase with the concentration of the free carbonic acid, but no law was deduced. For some time past I have been engaged upon an investigation of the solubility of calcium and magnesium carbonates in conjunction with Mr. P. V. Lloyd, the results of which will shortly be published. In consequence of the experience thus gained, it occurred to me to see whether Free's results exhibited any regularities similar to those found for the other carbonates, and whether these could not be deduced from the principles of chemical equilibrium.

Assuming that the solid ground substance is $\mathrm{CuCO}_{3} \cdot \mathrm{Cu}(\mathrm{OH})_{2}$, and that the copper exists in solution as bicarbonate, the reaction would be-

$$
\mathrm{CuCO}_{3} \cdot \mathrm{Cu}(\mathrm{OH})_{2}+3 \mathrm{H}_{2} \mathrm{CO}_{3}=2 \mathrm{Cu}\left(\mathrm{HCO}_{3}\right)_{2}+2 \mathrm{H}_{2} \mathrm{O} \text {; }
$$

or, since the bicarbonate must be split into copper and $\mathrm{HCO}_{3}$ ions-

$$
\mathrm{CuCO}_{3} \cdot \mathrm{Cu}(\mathrm{OH})_{2}+3 \mathrm{H}_{2} \mathrm{CO}_{3}=2 \mathrm{Cu}+4 \mathrm{HCO}_{3}+2 \mathrm{H}_{2} \mathrm{O} \text {. }
$$

The active mass of the solid carbonate and of the water being constant, we shall have the condition of equilibrium as follows: $\frac{\mathrm{Cu}^{2} \times \mathrm{HCO}_{3}{ }^{4}}{\mathrm{H}_{2} \mathrm{CO}_{3}{ }^{3}}=k$, where $k$ is a constant and the other symbols stand for ionic concentrations. 
If no other copper salt or bicarbonate be present, the whole of the copper in solution will practically exist as bicarbonate, and the concentration of the copper ions will always be half that of the $\mathrm{HCO}_{3}$ ions, or $\mathrm{Cu}=\frac{1}{2} \mathrm{HCO}_{3}$. Hence for this case we have-

$$
\frac{\mathrm{Cu}^{0}}{\mathrm{H}_{2} \overline{\mathrm{CO}_{3}}{ }^{3}}=\frac{k}{16}, \text { or } \underset{\mathrm{H}_{2} \overline{\mathrm{CO}_{3}}}{\mathrm{Cu}^{2}}=\frac{\sqrt[3]{\frac{k}{\sqrt{16}}}}{\sqrt[3]{16}}=\text { constant }
$$

In other words, the square of the dissolved copper ions should be proportional to the free carbonic acid. In Free's experiments the concentration of the copper must be multiplied by the degree of ionisation of the copper bicarbonate, which may be taken as equal to that of copper chloride at the same concentration. These figures not being to hand, I have assumed the same degree of ionisation as copper sulphate. Further, the free carbonic acid has been deduced from the total on the assumption that the copper existed as basic carbonate, and must therefore be corrected on the basis of bicarbonate. The correction is not large, but $I$ have made it. The results are expressed in mgms, per litre.

\begin{tabular}{|c|c|c|c|c|}
\hline Copper. & Ionisation. & Ions. & $\mathrm{H}_{2} \mathrm{CO}_{3}$. & $\mathrm{Cu}^{2} / \mathrm{H}_{2} \mathrm{CO}_{3}$. \\
\hline $\begin{array}{r}1 \cdot 5 \\
8 \cdot 3 \\
13 \cdot 7 \\
17 \cdot 0 \\
25 \cdot 7 \\
28 \cdot 0 \\
31 \cdot 0 \\
33 \cdot 7 \\
34 \cdot 8 \\
35 \cdot 3 \\
39 \cdot 7\end{array}$ & $\begin{array}{l}- \\
0.94 \\
0.93 \\
0.92 \\
0.91 \\
0.90 \\
0.89 \\
0.88 \\
0.87 \\
0.86 \\
0.85\end{array}$ & $\begin{array}{r}\overline{7 \cdot 80} \\
12 \cdot 74 \\
15 \cdot 64 \\
23 \cdot 38 \\
25 \cdot 20 \\
27 \cdot 59 \\
29 \cdot 65 \\
30 \cdot 28 \\
30 \cdot 35 \\
33 \cdot 75\end{array}$ & $\begin{array}{r}\overline{149} \\
263 \\
330 \\
716 \\
830 \\
929 \\
1,123 \\
1,187 \\
1,231 \\
1,508\end{array}$ & $\begin{array}{l}-\overline{408} \\
0.617 \\
0.741 \\
0.763 \\
0.765 \\
0.819 \\
0.783 \\
0.772 \\
0.748 \\
0.755\end{array}$ \\
\hline
\end{tabular}

In the first experiment the carbonic acid cannot be zero, but will be determined by the hydrolysis of the carbonate. This also affects the next two figures, but after this the value of $\mathrm{Cu}^{2} / \mathrm{H}_{2} \mathrm{CO}_{3}$ shows satisfactory constancy. The law above deduced therefore holds good between wide limits.

Free's experiments also show that calcium sulphate and small amounts of sodium chloride do not much affect the solubility, but that large amounts slightly increase it. Salts, however, which yield either the copper or $\mathrm{HCO}_{3}$ ion should depress the solubility; accordingly, we find that sodium bicarbonate greatly diminishes the solvent action. It is of interest to see if Free's results follow the law deducible from the equilibrium, which is the same that we have found experimentally to hold good for calcium carbonate.

Since $\frac{\mathrm{Cu}^{2} \times \mathrm{HCO}_{3}{ }^{4}}{\mathrm{H}_{2} \mathrm{CO}_{3}{ }^{3}}=k$, it follows that when the free carbonic acid is kept, the same the value of $\mathrm{Cu}^{2} \times \mathrm{HCO}_{3}^{4}$ will be constant, or, what is the same thing, $\sqrt{\mathrm{Cu}} \times \mathrm{HCO}_{3}$ should be constant. The square root of the dissolved copper should 
be proportionate to the total bicarbonate ions. We may express the bicarbonate ions in terms of their equivalent in copper, remembering that the results must be multiplied by two, since there are always two ions of $\mathrm{HCO}_{3}$ for each one of copper. The value of the constant for $\mathrm{H}_{2} \mathrm{CO}_{3}=1,200$ works out to 325 . I have applied these considerations to the figures given by Free.

Effect of Sodium Bicarbonate.

\begin{tabular}{|c|c|c|c|c|c|c|c|c|}
\hline Copper. & Ionisation. & $=$ Ions. & $\sqrt{\mathrm{Cu}}$. & $\begin{array}{c}\text { Cu equiva } \\
\text { lent to } \\
\mathrm{NaHCO}_{3} .\end{array}$ & Ionisation. & $=$ Ions. & $\begin{array}{c}\text { Copper }= \\
\text { total } \\
\mathrm{HCO}_{3} \text { ions }\end{array}$ & $\begin{array}{l}\sqrt[2]{\mathrm{Cu} x} \\
\mathrm{HCO}_{3}\end{array}$ \\
\hline 35 & 0.86 & $30 \cdot 1$ & $5 \cdot 486$ & - & - & $\ldots$ & $60 \cdot 2$ & 330 \\
\hline 27 & 0.90 & $24 \cdot 3$ & 4.930 & $5 \cdot 94$ & 0.95 & $5 \cdot 64$ & $59 \cdot 88$ & 295 \\
\hline 10 & $0 \cdot 94$ & $9 \cdot 4$ & $3 \cdot 067$ & $59 \cdot 44$ & 0.90 & $53 \cdot 50$ & $125 \cdot 80$ & 385 \\
\hline \multicolumn{9}{|c|}{ Effect of Calcium Bicarbonate. } \\
\hline 35 & 0.86 & $30 \cdot 1$ & $5 \cdot 486$ & - & - & - & $60 \cdot 2$ & 330 \\
\hline 25 & 0.91 & $22 \cdot 75$ & $4 \cdot 77$ & $6 \cdot 30$ & 0.95 & 5.98 & $57 \cdot 56$ & 274 \\
\hline 7 & 0.94 & 6.58 & 2.536 & $63 \cdot 00$ & 0.90 & $56 \cdot 70$ & $126 \cdot 55$ & 321 \\
\hline
\end{tabular}

I have neglected the cases in which the copper is reduced to about $1 \mathrm{mgm}$., since the solubility is then not greater than that in pure water.

Considering the fact that free carbonic acid was only approximately the same, and that the ionisation factors are uncertain, I think that the constancy of the product is good enough to show that the law deduced holds good. These results lead one to expect that similar regularities will be found for the carbonates of other heavy metals. It has been shown by Mikusch (Zeit. anorg. Chem., 1907, 56, 365) that, except $\mathrm{ZnCO}_{3}$ (corresponding to calamine), the only other carbonate of zinc is $2 \mathrm{ZnCO}_{3} \cdot 3 \mathrm{Zn}(\mathrm{OH})_{2} \cdot \mathrm{H}_{2} \mathrm{O}$, corresponding to the mineral hydrozincite. I have recently examined a deposit which was formed in a spring water containing free carbonic acid, where it was heated by proximity to a boiler after passing through galvanised iron pipes. The pipe was almost completely blocked by the deposit, which had exactly the composition of hydrozincite. Assuming that this is the ground substance, and that the reaction is $2 \mathrm{ZnCO}_{3} \cdot 3 \mathrm{Zn}(\mathrm{OH})_{2}+8 \mathrm{H}_{2} \mathrm{CO}_{3}=5 \mathrm{Zn}\left(\mathrm{HCO}_{3}\right)_{2}+6 \mathrm{H}_{2} \mathrm{O}$, the equilibrium would be governed by the condition $\mathrm{Zn}^{15} \times \mathrm{H}_{2} \mathrm{CO}_{3}{ }^{8}=k$, or $\mathrm{Zn}^{1.875}=k \mathrm{H}_{2} \mathrm{CO}_{3}$. This would not be very different from $\mathrm{Zn}^{2}=k \mathrm{H}_{2} \mathrm{CO}_{3}$.

Similarly, since it has been shown by Hawley (Journ. Phys. Chem., 1906, 10, 654) that the only basic lead carbonate is $2 \mathrm{PbCO}_{3} \cdot \mathrm{Pb}(\mathrm{OH})_{2}$, we should have the law $\mathrm{Pb}^{9}=k \mathrm{H}_{2} \mathrm{CO}_{3}^{4}$, or $\mathrm{Pb}^{2 \cdot 2}=k \mathrm{H}_{2} \mathrm{CO}_{3}$, again approximating to the same law.

In all three cases the effect of bicarbonate would be to diminish the solubility according to the law $\sqrt{\mathrm{M}} \times \mathrm{HCO}_{3}=$ constant, when the carbonic acid is kept constant. This explains the fact of the protective action of calcium in solution as bicarbonate upon waters which act upon lead and zinc. Evidently the solvent action will be a function of both the free carbonic acid and the total bicarbonates. 
THE ANALYST.

When the hydrolysis of these carbonates has been properly investigated, we shall probably be on the way to a satisfactory explanation of the action of natural waters upon lead and zinc. 